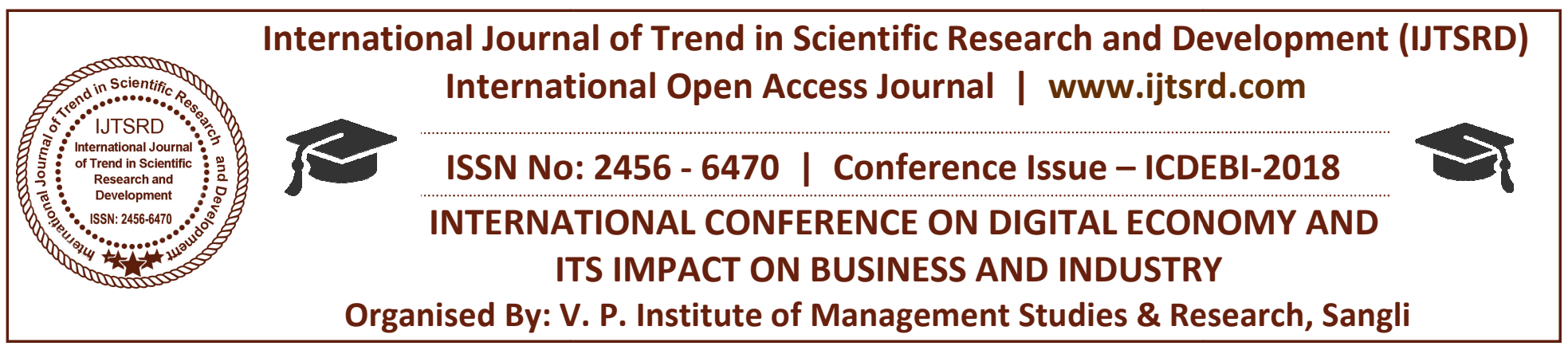

\title{
Digital Transformation of Travel \& Tourism In India
}

\author{
Dr. R. A. Rathi \\ Assistant Professor, V. P. Institute of Management Studies \& Research, \\ Sangli, Maharashtra, India \\ Affiliated to Shivaji University, Kolhapur, Maharashtra, India
}

\begin{abstract}
Digital innovation is transforming the way we live, work and run businesses it has global impact on economies, sectors and industries. The commencement of the Digital India programme in 2014 led the country into the League of Nations that is revamping their economies and governance with the power of technology. Since then, Digital India has affected almost all aspects of our lives, ranging from work, travel, communication to shopping, education and healthcare. India is going to be digital and travel and tourism are no exceptions to it. India has been ranked 51st out of 63 countries in the 2017 IMD
\end{abstract} World Digital Competitiveness ranking. Technology today plays a vital role in shaping the travel industry. With the increase in internet penetration and availability of smart phones India's Travel sector has expanded in the recent years. Among the service sectors in India, the tourism and hospitality industry has emerged as one of the major drivers of growth. The rich cultural and historical inheritance variety in flora and fauna and places of natural beauty spread across the country has enriched Tourism in India. Key advancements in the travel space move around five themes, namely Artificial Intelligence (AI), Big Data, mobile applications, social media and Virtual/Augmented Reality (VR/AR). These advancements could enrich travel experiences through direct and flexible interactions with customers. This paper attempts to explore a broad view on the economic contribution of travel in India, trends, challenges and consequences of digital travel, the role of new technologies and automation in streamlining the business processes across the value chain thereby canvassing picture of digital travel revolution unfolding.

KEYWORDS: Artificial Intelligence (AI), Big Data, Digital innovation, Social media and Virtual/Augmented Reality (VR/AR).

\section{INTRODUCTION}

Travel and tourism is among the largest service provider industry in India. The rich cultural and historical inheritance variety in flora and fauna and places of natural beauty spread across the country has enriched Tourism in India. This sector aims to develop and promote tourism, retain the image of India as a tourist centric destination and expanding the present tourism products. Tourism in India is a great employment generator in different areas like accommodations, transportation, attractions sites, information offices photography etc. It is a significant source of foreign exchange in India. The minister of tourism SHRI. K. J. ALPHONS said that the Earnings from foreign exchange in tourism have grown by more than 17 per cent in April 2018 over April 2017. Tourism has provided employment to 41.6 million people in 2017 contributing $8 \%$ of the total employment opportunities generated in India in 2017. It is among the top 10 sectors to attract the highest Foreign Direct Investment (FDI). From April 2000December 2017, the hotel and tourism sector attracted around US\$ 10.90 billion of FDI.

\section{OBJECTIVE OF THE STUDY}

1. To understand the economic contribution of Indian tourism industry.

2. To study digital transformation in travel.

3. To study tools and technology for digital travel.

4. To study challenges and way forward for digital travel in India. 


\subsection{DEFINING THE ECONOMIC CONTRIBUTION OF TRAVEL \& TOURISM}

One of the important economic activities in most countries around the world is Travel \& Tourism., The industry has significant direct economic as well as indirect and induced impact. The following diagram shows the economic contribution of travel \& tourism.
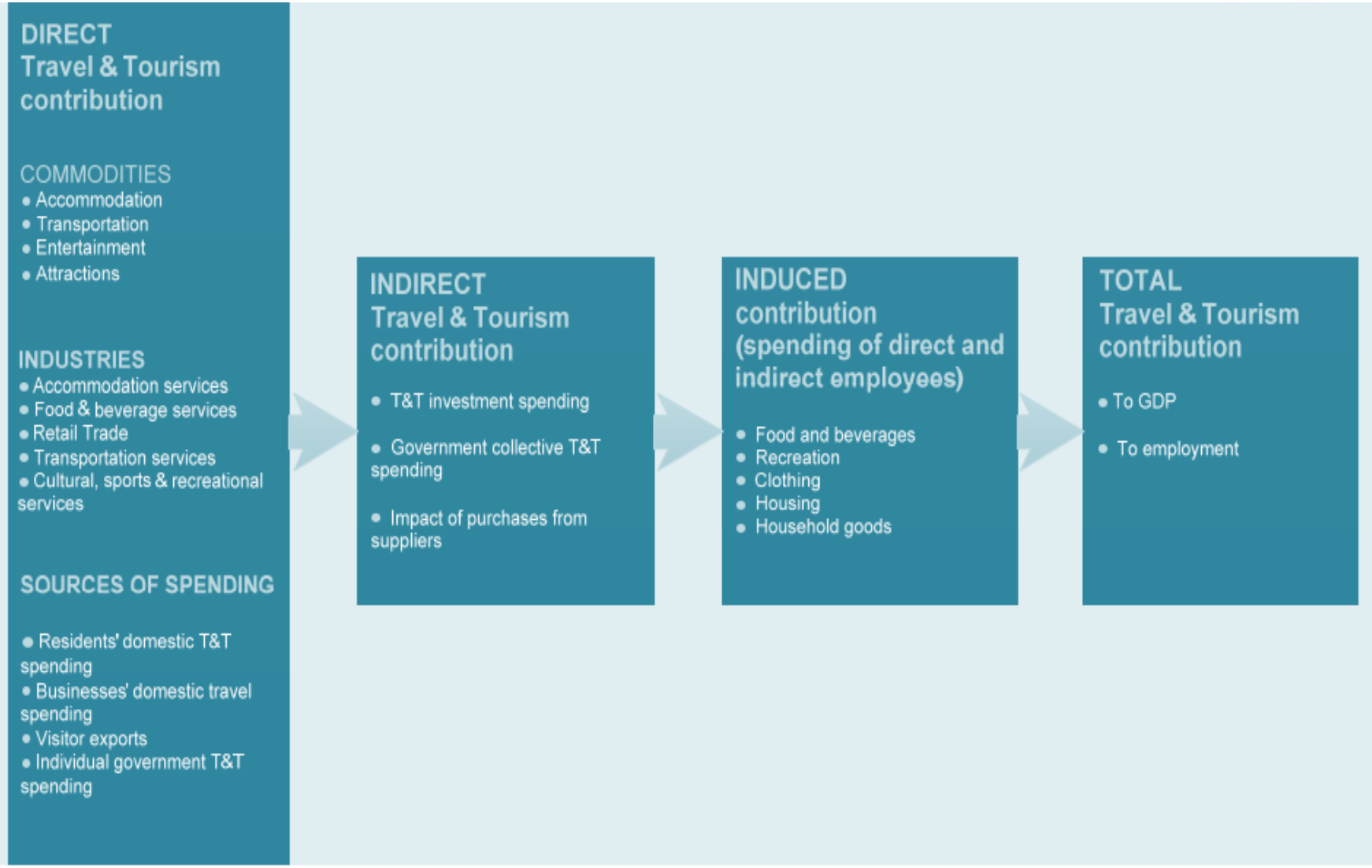

Source: https://www.wttc.org/-/media/files/reports/economic-impact-research/countries-2018

\section{Direct contribution to GDP}

GDP generated by industries that deal directly with tourists, including hotels, travel agents, airlines and other passenger transport services, as well as accommodation services, food and beverages services, retail trade and cultural sports and recreational services that deal directly with tourists. It is equal to total internal Travel \& Tourism spending, within a country deducted by the purchases made by those industries (including imports).

\section{Direct spending impacts}

VISITOR EXPORTS It includes expenditure within the country by foreign tourists for both business and leisure trips, spending on transport, but does not include international spending on education.

\section{Domestic travel \& tourism spending}

It is spending within a country by that country's residents for both business and leisure trips. It excludes multi-use consumer durables as they are not purchased only for tourism purposes.

\section{Government individual spending}

It is expenditure by the government on Travel \& Tourism services directly provided to visitors, such as cultural services (eg museums) or recreational services (eg national parks).

\section{Internal tourism consumption}

It is the total revenue generated within a country from visitor exports, domestic spending and government individual spending by industries that deal directly with tourists. It excludes spending abroad by residents.

\section{Business travel \& tourism spending}

It is expenditure on business travel within a country by residents and foreign visitors.

Leisure travel \& tourism spending 
It is expenditure on leisure travel within a country by residents and non resident visitors

\section{Direct contribution to employment}

It is the number of direct jobs within Travel \& Tourism industry.

\section{Total contribution to employment}

It comprises of the number of jobs generated directly in the Travel \& Tourism sector plus the indirect and induced contributions

\section{Indirect and induced impacts}

Indirect contribution

The following three factors are contributors to GDP and jobs:

Capital investment: It comprises of capital investment by all industries directly involved in Travel \& Tourism. This also constitutes investment expenditure by other industries on particular tourism resources such as new visitor accommodation and passenger transport equipment, as well as restaurants and leisure facilities for explicit tourism use.

Government collective spending: It is Government expenditure for general tourism activity. This comprises of national as well as regional and local government spending. For example, it includes visitor information services, administrative services, tourism promotion and other public services.

Supply-chain effects: It is the purchases of domestic goods and services directly by different industries within Travel \& Tourism as inputs to their final tourism output.

Induced contribution The expenditure by those who are directly or indirectly employed by Travel \& Tourism.

The following table and graph presents the total contribution of travel \& tourism to GDP

\begin{tabular}{|c|c|c|c|c|c|c|c|c|}
\hline $\begin{array}{c}\text { INDIA (INRbn, real 2017 } \\
\text { prices) }\end{array}$ & 2012 & 2013 & 2014 & 2015 & 2016 & 2017 & $2018 \mathrm{E}$ & $2018 \mathrm{~F}$ \\
\hline Direct & $4,149.8$ & $4,413.1$ & $4,736.9$ & $5,181.2$ & $5,676.6$ & $5,943.3$ & $6,392.7$ & 12,678 \\
\hline Indirect & $5,255.7$ & $5,589.1$ & $5,999.2$ & $6,561.9$ & $7,189.3$ & $7,527.2$ & $8,096.3$ & 16,057 \\
\hline Induced & $1,207.6$ & $1,276.3$ & $1,381.1$ & $1,465.7$ & $1,573.3$ & $1,659.3$ & $1,771.8$ & $3,092.1$ \\
\hline
\end{tabular}

Source: TRAVEL \& TOURISM ECONOMIC IMPACT 2018

Figure: Graph showing total contribution of travel \& tourism to GDP

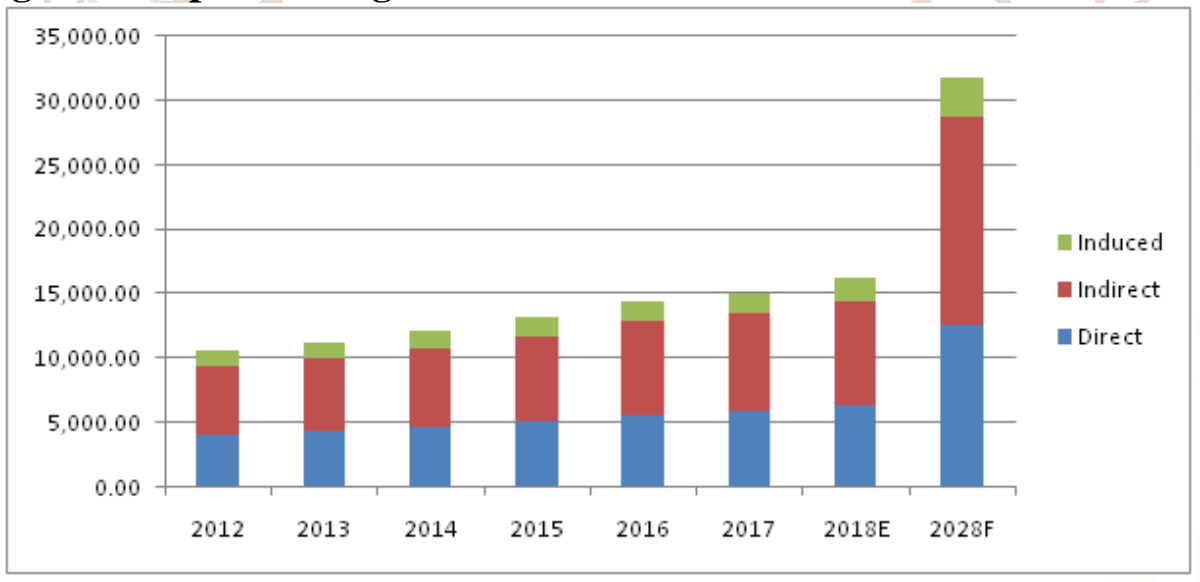

The above table and graph shows the direct, indirect and induced contribution of travel \& tourism to GDP from 2012 to 2017, 2018E and 2028F. The graph shows a continuous rising trend indicating a bright prospect for the industry. Further the following diagram gives the breakdown of travel \& tourism's contribution to GDP and Employment 2017. 


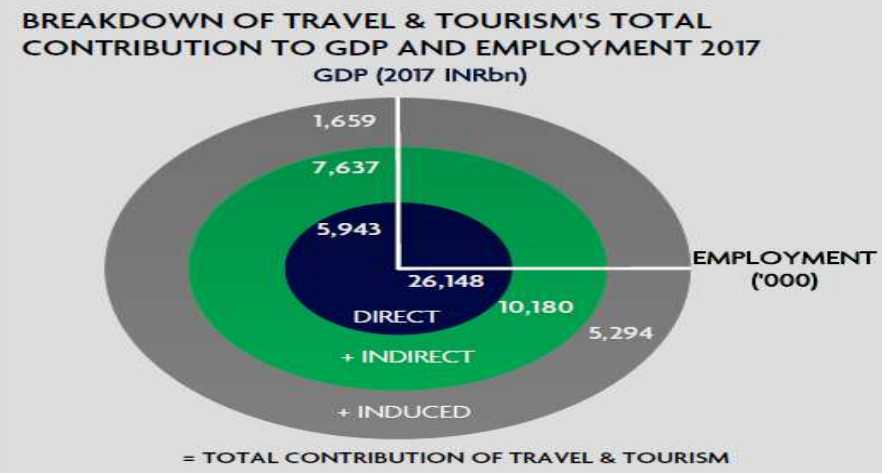

The above figure shows continued and steady growth with rise in Foreign Tourist Arrivals (FTAs) and growth in Foreign Exchange Earnings during 2017. The key drivers for this rapid growth are growing disposable incomes and the rise of millennials as the 'chief wage earners', who account for 47 per cent of the working age population. Along with it, the increasing number of smart phones, Internet and technology-driven tools are acting as a catalyst for speedy digitisation of the travel and tourism sector.

\subsection{DIGITAL TRANSFORMATION TRAVEL}

The travel and hospitality sector is speedily developing with the increasing acceptance of various tools, technologies and digital platforms first and foremost to improve customer experience, build strong loyalties and run businesses efficiently. These include mobile applications, social media, Big Data analytics, artificial intelligence (AI) and machine learning, virtual reality (VR) and augmented reality (AR).

Travel port which is the leading Travel Commerce Platform, published the results of a Global Traveller Survey of 11,000 people worldwide that highlights the use of digital tools when planning, booking and experiencing a journey.

The main results from the global report are:

When planning a trip:

- $81 \%$ use peer to peer reviews when researching a trip

- $47 \%$ use voice search, using devices such as Amazon Echo and Google Home, when researching a trip

- Nearly $25 \%$ of over 55 year olds use a smart phone to research a trip

When booking a trip:

- Over $33 \%$ of travellers book their trip on a mobile device
- $61 \%$ avoid hotels that charge for Wi-Fi

When on the trip:

- $70 \%$ of travellers believe that digital boarding passes make travelling so much easier

- $60 \%$ of travellers feel that a good digital experience is important when choosing an airline

- $44 \%$ of travellers rely on their smart phone at their destination

When at the destination:

- Travelers use an average of 16 different categories of apps when traveling

- $75 \%$ of travelers leave reviews on review sites

Source: https://www.travelport.com/company/mediacenter/press-releases/2017-11-08/travelport-global-

survey-highlights-different-digital

In the same way Indian travellers are becoming tech friendly having following characteristics as displayed in different research and statistics published in 2017

Most travellers go online, and 67 per cent even use voice search while researching for a trip

71 per cent use smart phones for research and booking, and 82 per cent would appreciate digital boarding passes and e-tickets for convenience

87 per cent use videos and photos posted by friends as part of their travel research, and 83 per cent believe that being able to stay in touch is most important while travelling

85 per cent use price comparison sites to look for deals, and 58 per cent agree spending considerable time to find best price

91 per cent use review sites, though 52 per cent are wary of their trustworthiness

75 per cent choose hotels that do not charge for Wi-Fi

\subsection{TOOLS AND TECHNOLOGIES FOR DIGITAL TRAVEL}

The arrival of technology is promoting a change in the travel and tourism industry regarding how companies interact with customers. As a result, travel companies are adopting various technologies to improve operational efficiencies and meet customers' expectations, according to leading data and Analytics Company,

The tools and technologies that are finding major applications in the travel sector include mobile 
applications, social media, Big Data analytics, AI, machine learning, VR, and AR.

\section{Mobile applications}

Most of the interactions with the customers are through the mobile. The statistics shows the number of mobile phone users in India from 2013 to 2019. In 2017 the number of mobile phone users in India is expected to rise to 730.7 million. In the same year the number of smart phone users in India is assumed to reach 340 million and could reach almost 468 million by 2021 .

An OTA is a travel website that specializes in the sale of travel products to consumers. Some agencies sell a variety of travel products including flights, hotels, car rentals, cruises, activities, and packages.The following figure presents market share of OTA in India.

\section{Market Share}

\section{Big Data analytics}

Big data analytics helps in structured decision making. It personalises customer experience, make use of dynamic pricing and channelize marketing efforts. It helps the business in the travel and tourism industry to take instantaneous decisions as per the varying customer demands.

\section{Artificial Intelligence}

AI in the form of chat bots, virtual assistants and even robots is increasingly being employed across the travel sector. In addition, machine learning makes these tools smarter over time and helps improve customer experience. For effective use of recommendation mechanism to deliver a good user experience over avenues like holiday packages, car rentals, hotels, and cruise lines, among others online travel agencies have made use of AI and ML.

\section{Virtual Reality (VR) and Augmented reality (AR)}

A panorama view of vacation could be obtained by VR. Augmented reality, or AR, is a digital technology, which changes a person's perception of their physical surroundings, when viewed through a particular device. The augmented reality is similar to virtual reality, but AR does not replace the realworld environment, but supplements it by laminating it with the digital components. Augmented reality has become increasingly popular within the travel industry as it enables hotels and other businesses operating in this field to develop the physical environments they are actually trying to persuade customers to visit by including local sights and hotel rooms.

\subsection{CHALLENGES FOR DIGITAL TRAVEL IN INDIA}

Lack of enabling infrastructure Digitisation of travel is highly dependent on factors such as highspeed Internet connectivity, seamless digital payment solutions and a robust regulatory and policy framework. While positive strides are being made in each of these aspects, India stil considerably lags in comparison to most nations globally.

Disintegrated payments The issues concerning payments include lack of integration between the payment systems of banks, mobile wallets and merchants, high cost of digital transactions and lack of facilitation of foreign currency payments.

Threats to data security and privacy With increasing digitisation in travel especially the growth of mobile wallets, Unified Payments Interface (UPI), internet banking and other such digital initiatives taken by the government - the risks of data security are bound to rise. 


\subsection{WHAT IS THE WAY FORWARD}

With the advent of technology, the Indian travel and hospitality sector is expected to see more of innovative solutions and services such as AR city tours, smart tourism, robots for security and housekeeping, smart luggage, radio frequency identification (RFID)/facial recognition technology to open hotel doors, driverless/self-parking cars and air taxis over the foreseeable future. With such developments at the front the government and players in the sector are expected to take certain actions going forward, which include

\section{For government}

$>$ Easier identification through Aadhaar, improved access to banking infrastructure and point-of-sale (POS) machines, and availability of internet connectivity and telecommunication networks are some steps for enabling a flawless experience for travellers.

> IT literacy is a must condition for the digital services to catch up amongst the masses. Steps must be taken to introduce skills required in the direction of digital economy at early levels, particularly at schools.

$>$ In commercial and financial transactions there is a greater risk of phishing attacks. To counter this, the Government of India can look at implementing its own General Data Protection Regulation (GDPR).

\section{For businesses}

$>$ Branded hotel chains in India are expected to continue investing in digital technologies and platforms. Enhancing pre-booking as well as postbooking experiences would be of supreme importance.

$>$ Loyalty would take preference for hotels, airlines as well as OTAs. India would continue to remain a price sensitive market.

$>$ Things to do at a destination would be a noteworthy area of focus for online travel companies, especially metasearch engines, as they are venturing into it as merchants - allowing them to earn higher margins

$>$ Direct bookings would be emphasised more by hotels and airlines.

\section{CONCLUSION}

The government's e-tourist visa programme continues to gain attraction, with a sharp rise in applications in October 2016. Digital Solutions enhancements are the need of the hour as it really does help the flow of travel. Globally, consumers are looking for extra value from their travel spends and in India, travelling is part of people's ambition. The industry needs to address the evolving travel perceptions and behaviors by offering specialized services for each need. The way that tourists discover, book and organise trips is changing. In todays digital world developing at a increasing pace travel agencies have to adapt to offer a seamless online experience. Some of the urgent priorities for travel start-ups include efficiency, skill and software expertise.

\section{REFERENCES}

1. Auroubindo Ganesh and Dr. Madhavi, C. (2007). Jan-June, "Impact of Tourism on Indian Economy - A Snapshot" Journal of Contemporary Research in Management, Volume-1, No.1, 2 PP. 235-240.

2. Honey, Martha and Gilpin, Raymond, Special Report, (2009), "Tourism in the Developing World -Promoting Peace and Reducing Poverty"

3. https://home.kpmg.com/.../ficci-expedition-travelhospitality-technology-innovation Mar 20, 2018

4. https://ficci-thtc.com/2017

5. https://www.wttc.org//media/files/reports/economic-impactresearch/.../india2018.

6. https://www.travelport.com/company/mediacenter/press-releases/2017-11-08/travelportglobal-survey-highlights-different-digital 